\title{
Noninvasive epicutaneous transfontanelle intracranial pressure monitoring in children under the age of 1 year: a novel technique
}

\author{
Bedjan Behmanesh, MD, ${ }^{1}$ Matthias Setzer, MD, ${ }^{1}$ Anika Noack, MD, ${ }^{1}$ Marco Bartels, MD, ${ }^{2}$ \\ Johanna Quick-Weller, MD, ${ }^{1}$ Volker Seifert, MD, PhD, ${ }^{1}$ and Thomas M. Freiman, MD${ }^{1}$ \\ Departments of ${ }^{1}$ Neurosurgery and ${ }^{2}$ Neuropaediatrics, Goethe University, Frankfurt am Main, Germany
}

Monitoring of intracranial pressure (ICP) may be indicated in children with traumatic brain injury, premature intraventricular hemorrhage, or hydrocephalus. The standard technique is either a direct measurement with invasive intracranial insertion of ICP probes or indirect noninvasive assessment using transfontanelle ultrasonography to measure blood flow. The authors have developed a new technique that allows noninvasive epicutaneous transfontanelle ICP measurement with standard ICP probes. They compared the ICP measurements obtained using the same type of standard probe used in 2 different ways in 5 infants (age $<1$ year) undergoing surgery for craniosynostosis. The first ICP probe was implanted epidurally (providing control measurements) and the second probe was fixed epicutaneously on the skin over the reopened frontal fontanelle. ICP values were measured hourly for the first 24 hours after surgery and the values obtained with the 2 methods were compared using Bland-Altman 2-methods analysis.

A total of 110 pairs of measurements were assessed. There was no significant difference between the ICPs measured using the epicutaneous transfontanelle method (mean $13.10 \mathrm{~mm} \mathrm{Hg}$, SEM $6.68 \mathrm{~mm} \mathrm{Hg}$ ) and the epidural measurements (mean $12.46 \mathrm{~mm} \mathrm{Hg}$, SEM $6.45 \mathrm{~mm} \mathrm{Hg} ; \mathrm{p}=0.4643$ ). The results of this analysis indicate that epicutaneous transfontanelle measurement of ICP is a reliable method that allows noninvasive ICP monitoring in children under the age of 1 year. Such noninvasive ICP monitoring could be implemented in the therapy of children with traumatic brain injury or intraventricular hemorrhage or for screening children with elevated ICP without invasive intracranial implantation of ICP probes.

http://thejns.org/doi/abs/10.3171/2016.3.PEDS15701

KEY WORDS noninvasive ICP monitoring; craniosynostosis; children; technique

$\mathrm{E}$ LEVATED intracranial pressure (ICP) is defined as ICP $>20 \mathrm{~mm} \mathrm{Hg}$ and is an important cause of secondary brain injury and morbidity in adults and children. Thus the assessment of ICP is considered crucial in patients with brain injuries. ${ }^{10}$ The aim of ICP-based treatment in these cases is to maintain adequate cerebral perfusion and avoid further damage to brain tissue.

ICP monitoring should especially be considered in cases of traumatic brain injury (TBI), which often occurs in young children (age 0-4 years), as underscored by data from the United States. ${ }^{17,18}$ The aim of ICP monitoring is to identify all those patients in need of intervention to avoid secondary brain injuries. ${ }^{3,5}$

The standard method of ICP monitoring in children is still the placement of an external intraventricular catheter with an ICP probe. ${ }^{5,10}$ However, this is an invasive tech- nique which carries the risk of infection, hemorrhage, and system malfunction. Hemorrhage occurs in approximately $7 \%-11 \%$ of patients after insertion of an invasive device for ICP measurement, ${ }^{1,4,12}$ and infection rates have been reported to range between $1 \%$ and $20 \% .^{8,9,14}$ In many cases, invasive ICP probes cannot be placed because of abnormal hemostasis. ${ }^{2,13}$

Noninvasive techniques are based on the use of indirect parameters observed with MRI or CT, or on the measurement of optic nerve sheath diameter or tympanic membrane displacement. Transcranial Doppler ultrasound measurement of blood flow also provides an indirect noncontinuous method of monitoring ICP. . $^{6,15}$

However, children under the age of 1 year usually have an open frontal fontanelle, which allows the epicutaneous placement of ICP probes. 


\section{Methods}

A 1-year prospective study of ICP measurement in infants undergoing craniosynostosis surgery was conducted to investigate the accuracy of transfontanelle ICP measurement (Fig. 1). To evaluate the new noninvasive method, it was necessary to compare our new method with the established invasive method of ICP measurement with ICP probes, which are placed intracranially. The setting of craniosynostosis surgery was proposed for the study, with comparison of epidural ICP with the epicutaneous transfontanelle pressure. We used standard intraparenchymal ICP probes (probe 3PN, Spiegelberg). The ICP was measured with a standard ICP monitor (ICP-Monitor HDM29.2, Spiegelberg).

Parents of infants undergoing craniosynostosis surgery were offered the opportunity to have their children considered for participation in this study after they had already made the decision for corrective surgery. Because the study involved comparison of readings obtained with an epidural ICP probe (Fig. 2) and readings obtained by means of transfontanelle measurement (Fig. 3), we obtained permission from parents to include their children in the study in the event that postoperative ICP monitoring was deemed clinically necessary during the procedure itself (i.e., if the operation was particularly long or the blood loss was greater than expected). In cases in which postoperative ICP monitoring was considered necessary, we placed an epidural ICP probe and then also taped an ICP probe to the child's scalp after the operation. In cases in which postoperative ICP monitoring was not considered necessary, no probe was placed and the child was excluded from the study.

For the transfontanelle ICP measurement, we used a wooden tongue depressor to hold the ICP probe securely against the fontanelle. The tongue depressor was cut to an appropriate length so that it could bridge the fontanelle, with the ends resting on bone, and then secured with SteriStrips or medical tape in such a way that the ICP probe was held tightly against the fontanelle without the need for additional force (Fig. 3).

The data were captured with the pneumatic sensors, as the Spiegelberg 3PN probe uses a small balloon ("air pouch") in the distal end of the catheter to register changes in pressure and additionally allows quantitative measurement of intracranial compliance. The air-pouch system consists of a hollow body connected to a pressure transducer by tubing. The pressure transducer, the electronic hardware, and the device for filling the air pouch are integrated into the brain-pressure monitor. Depending on the technique, monitoring can be done in the intraventricular, intraparenchymal, epidural, subdural, or subarachnoid compartment. The main advantage of this system is the automatic zeroing procedures performed by the monitor after insertion and hourly thereafter.11

Monitoring was performed with both methods (epidural

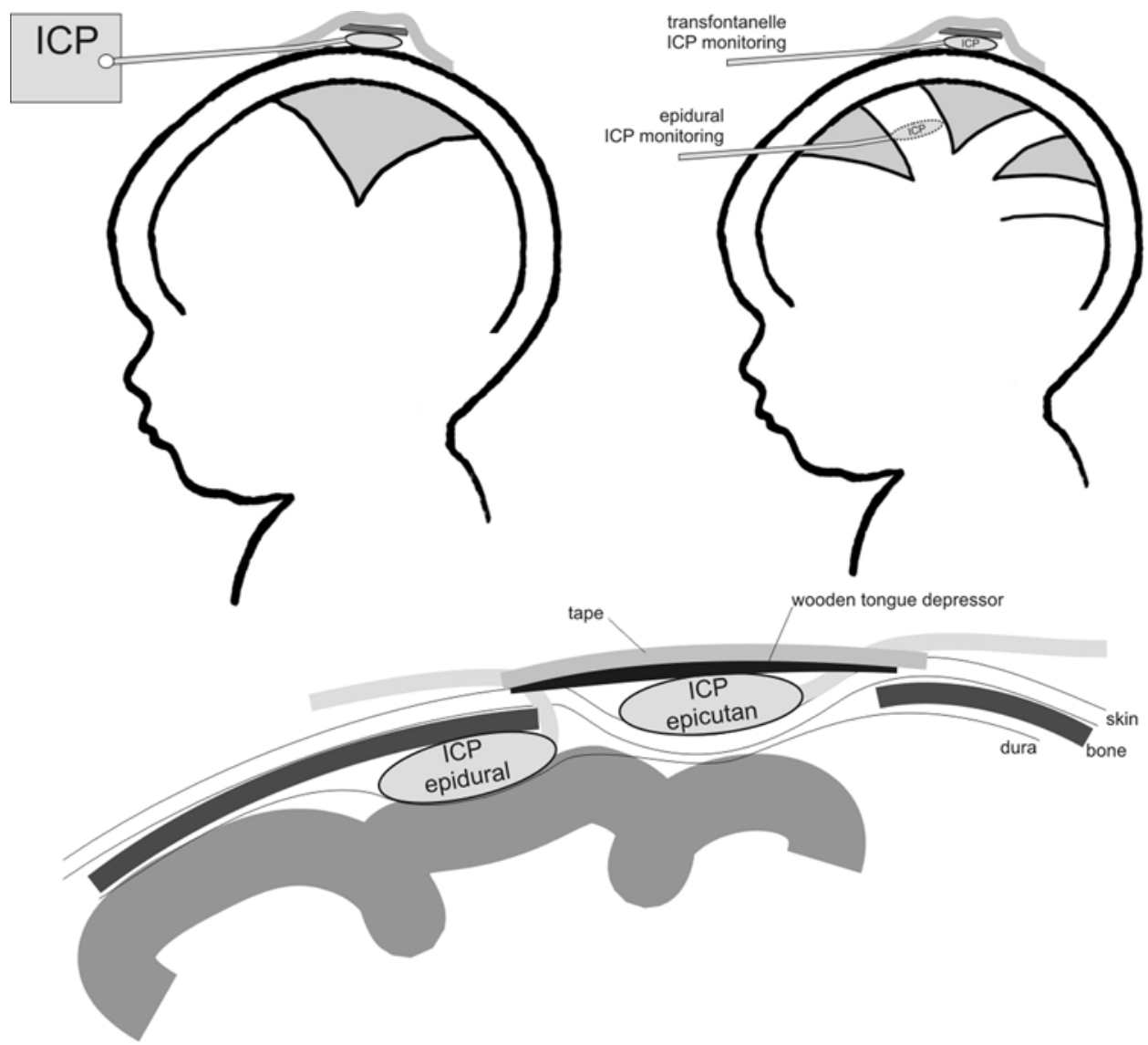

FIG. 1. Illustration of transfontanelle placement of ICP probes and epidural ICP monitoring. Epicutan = epicutaneous. Copyright Bedjan Behmanesh. Published with permission. 


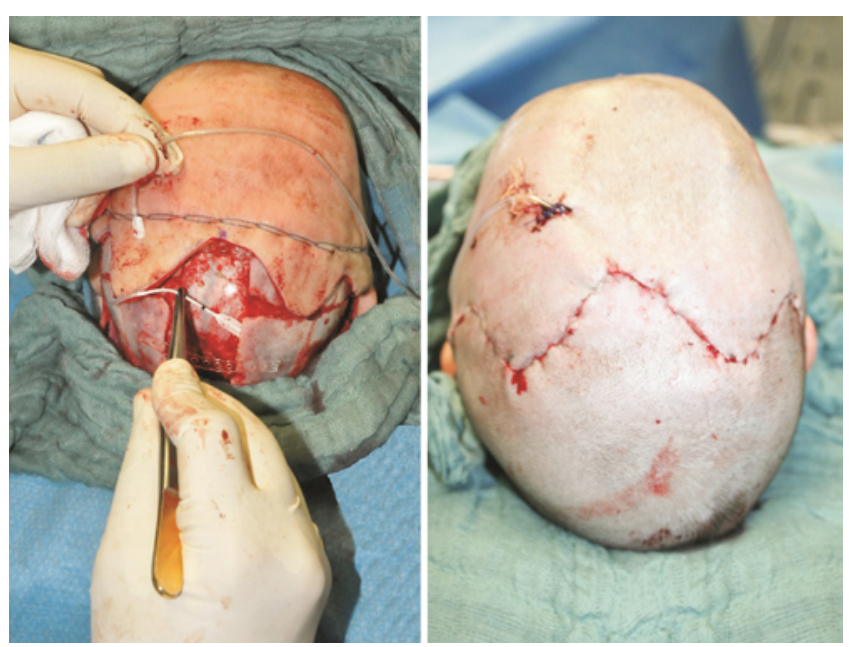

FIG. 2. Intraoperative placement of the epidural ICP probes that were used in this study to provide measurements for comparison with the measurements obtained with the transfontanelle method. Left: Photograph showing epidural ICP probe placement before skin closure. Right: View after skin closure with implanted epidural ICP device. Figure is available in color online only.

and transfontanelle epicutaneous) for at least 24 hours after surgery, and the ICP was recorded for purposes of our study at 1-hour intervals (Fig. 4). Both ICP probes were removed the day after surgery.

\section{Study Approval}

This study was approved by the ethics committee of the medical faculty of the University of Frankfurt am Main. Informed consent was obtained from the parents of all patients prior to surgery.

\section{Results}

Five children with nonsyndromic sagittal craniosynostosis under the age of 1 year were included in the study. All 5 patients underwent modified strip craniotomy. The surgery took between 180 and 300 minutes.

A total of 110 pairs of measurements were available for analysis. (Some sets of measurements were not available because the values were recorded hourly by staff members who sometimes forgot to include the value recorded with the transfontanelle technique.) There was no significant difference between the mean values for transfontanelle and epidural ICP measurement (transfontanelle, $13.10 \mathrm{~mm} \mathrm{Hg}$ [SEM $6.68 \mathrm{~mm} \mathrm{Hg}$ ]; epidural, $12.46 \mathrm{~mm} \mathrm{Hg}$ [SEM 6.45], p $=0.4643$ ). For analyzing the accuracy of our new method we used the Bland-Altman plot, which is the appropriate tool for analyzing the accuracy of a new measurement method in comparison with an already established one. The difference between the 2 paired measurements is plotted against the mean of the 2 measurements (Fig. 5). The statistical limits are calculated by using the mean and the standard deviation of the differences between 2 measurements.

The data show an acceptable distribution of ICP values. The values obtained with the noninvasive ICP monitoring method correspond with those obtained with the es-

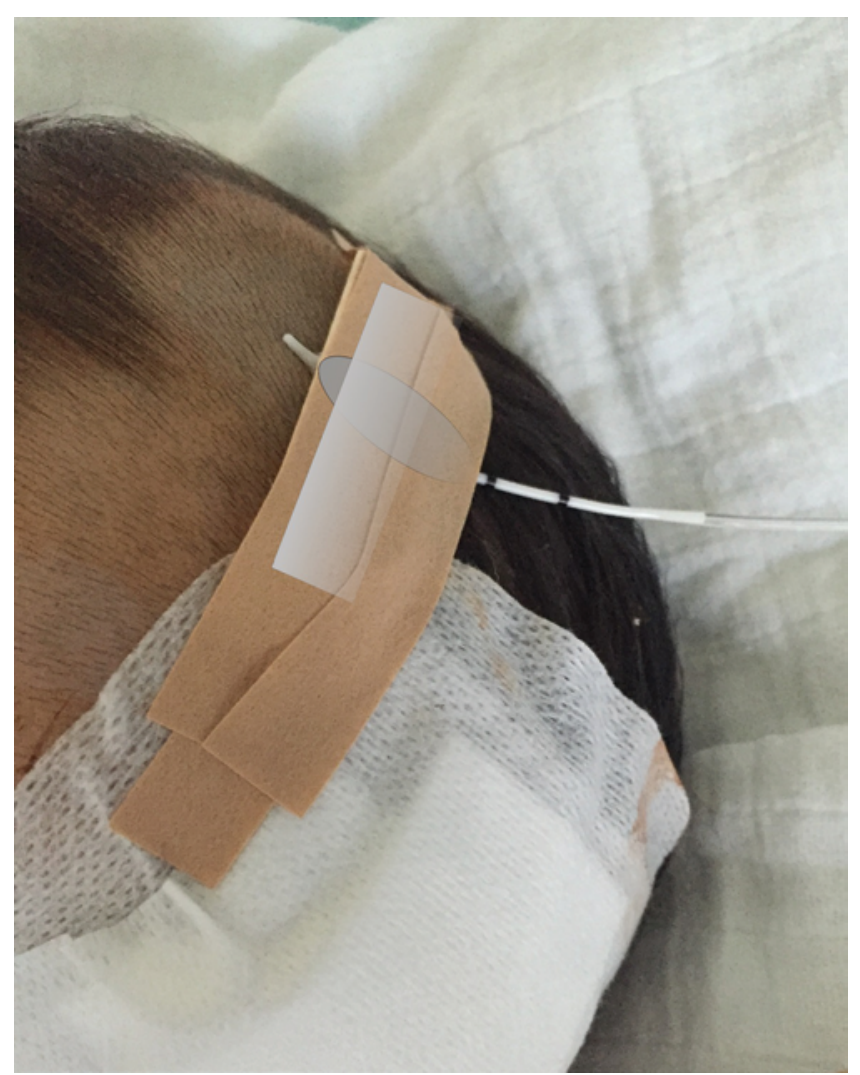

FIG. 3. Photograph showing the epicutaneous placement of the standard ICP probe with overlying wooden tongue depressor and tape. The gray oval was added to the photograph to demonstrate the position of the ICP probe. The white rectangle is a photographic artifact. Figure is available in color online only.

tablished method, and all measured values were within the statistic field that is defined by the limits of agreement (Fig. 5).

The correlation coefficient between epidural and transfontanelle ICP measurement was good $(\mathrm{y}=0.9298 \mathrm{x}+$ $0.3739 ; \mathrm{r}=0.95, \mathrm{p}<0.001$ ) (Fig. 6).

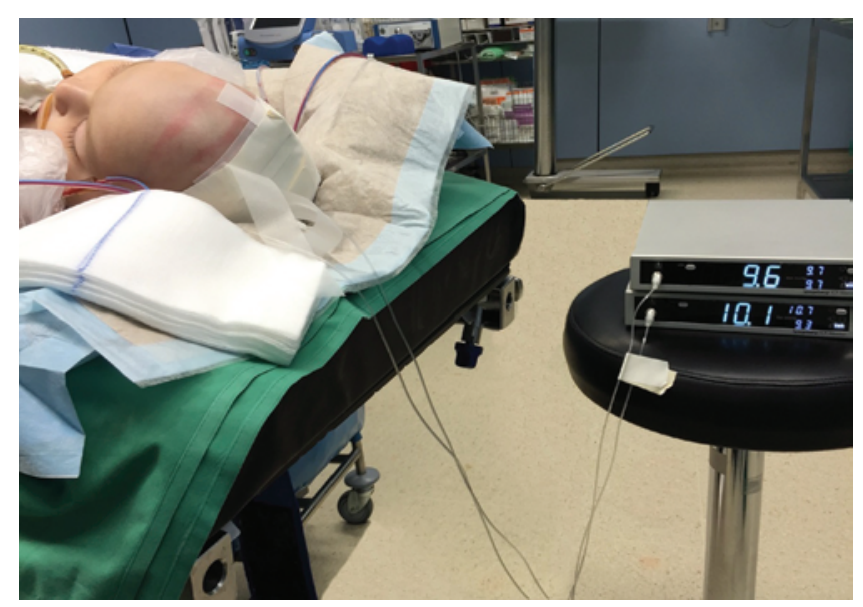

FIG. 4. Photograph obtained immediately after surgery showing simultaneous epidural and transfontanelle ICP monitoring. Figure is available in color online only. 


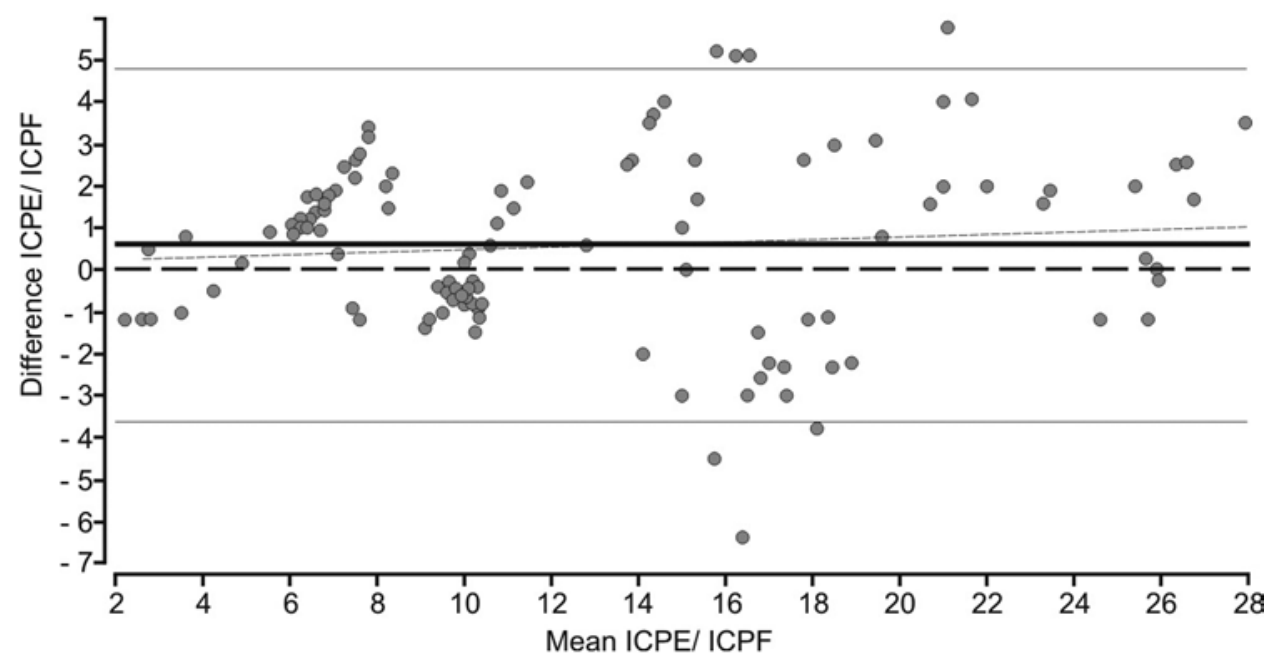

FIG. 5. Bland-Altman plot demonstrating good correspondence between the transfontanelle ICP and epidural ICP measurement methods. For 110 paired measurements (gray dots), the difference between the measurements in each pair (ICPE - ICPF; $y$-axis) is plotted against the average of the measurements in each pair ([ICPE + ICPF]/2; $x$-axis). The thick middle line represents the mean of the differences between the methods; the thin upper and lower lines represent the $95 \%$ limits of agreement. The broken line, below the thick horizontal line, represents the optimal zero line in case of correlation. ICPE = ICP measured by epidural method; ICPF = ICP measured by transfontanelle method.

\section{Discussion}

Our study demonstrates that transfontanelle ICP monitoring is a highly accurate noninvasive technique for the detection of increased ICP in infants under the age of 1 year. An advantage of this new method is the usage of established devices for ICP measurement. It does not require the purchase of any new device. Noninvasive ICP monitoring could be implemented in the treatment of and screening for increased ICP in patients under the age of 1 year.

A limitation of the present study is the basis of the comparison, namely, epidural measurements of ICP. This method was chosen to show the feasibility and accuracy of our new method, although we acknowledge that there is controversy about the accuracy of epidural ICP measurement compared with standard intraventricular or intraparenchymal measurement. Previous investigations focusing on the accuracy of extradural ICP monitoring have shown the disadvantage of overestimating ICP and the possibility of significant drifting of the probe over time. ${ }^{11}$

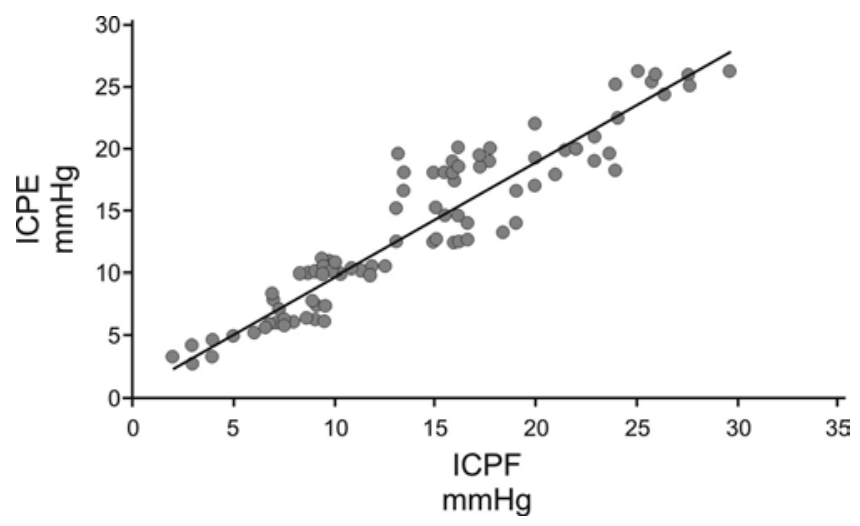

FIG. 6. Correlation between paired transfontanelle and epidural ICP measurements (gray dots), designated by ICPF and ICPE, respectively.
The advantage of using an epidural device is that it is less invasive and entails less risk of infection or intracranial hemorrhage than an intraparenchymal or intraventricular method.

The aim should be to compare our new method with the already proven criterion standard of ICP measurement, but in this setting there was no need for dura opening during the craniosynostosis surgery. Implanting an intraparenchymal or intraventricular device would not be ethically acceptable in this setting. Our primary aim was to show the feasibility of a noninvasive, epicutaneous method of ICP measurement. The next step of our work is to compare results achieved using this method with simultaneous intraventricular or intraparenchymal ICP measurement. Animal testing with simultaneously recorded intraventricular ICP monitoring may also be undertaken to establish the value of this new method.

Another limitation of the new method is the skin irritation caused by the fixative material (e.g., tape). The kind of fixative used and the subsequent interpretation was dependent on the investigator, but we were able to determine that the difference over the investigation period was negligible.

Despite recommendations of the guidelines for the management of pediatric TBI, ICP monitoring is used infrequently in these cases..$^{10}$ The decision not to monitor ICP often depends on analysis of clinical risks and potential benefits; it may be considered too invasive and risky in patients with improving Glasgow Coma Scale scores, and futile in moribund patients with catastrophic brain injuries. ${ }^{16}$ The method that we present here may provide an alternative that allows for more frequent use of ICP monitoring to screen for and help in the management of elevated ICP in very young patients.

\section{Acknowledgments} port.

We thank Anne Marina Heibel for her excellent technical sup- 


\section{References}

1. Adelson PD, Bratton SL, Carney NA, Chesnut RM, du Coudray HE, Goldstein B, et al: Guidelines for the acute medical management of severe traumatic brain injury in infants, children, and adolescents. Chapter 5. Indications for intracranial pressure monitoring in pediatric patients with severe traumatic brain injury. Pediatr Crit Care Med 4 (3 Suppl):S19S24, 2003

2. Alkhoury F, Kyriakides TC: Intracranial pressure monitoring in children with severe traumatic brain injury: National Trauma Data Bank-based review of outcomes. JAMA Surg 149:544-548, 2014

3. Anderson RC, Kan P, Klimo P, Brockmeyer DL, Walker ML, Kestle JR: Complications of intracranial pressure monitoring in children with head trauma. J Neurosurg 101 (1 Suppl):53-58, 2004

4. Binz DD, Toussaint LG III, Friedman JA: Hemorrhagic complications of ventriculostomy placement: a meta-analysis. Neurocrit Care 10:253-256, 2009

5. Citerio G, Andrews PJ: Intracranial pressure. Part two: Clinical applications and technology. Intensive Care Med 30:1882-1885, 2004

6. Eisenberg HM, Gary HE Jr, Aldrich EF, Saydjari C, Turner $B$, Foulkes MA, et al: Initial CT findings in 753 patients with severe head injury. A report from the NIH Traumatic Coma Data Bank. J Neurosurg 73:688-698, 1990

7. Gwer S, Sheward V, Birch A, Marchbanks R, Idro R, Newton $\mathrm{CR}$, et al: The tympanic membrane displacement analyser for monitoring intracranial pressure in children. Childs Nerv Syst 29:927-933, 2013

8. Hoefnagel D, Dammers R, Ter Laak-Poort MP, Avezaat CJ: Risk factors for infections related to external ventricular drainage. Acta Neurochir (Wien) 150:209-214, 2008

9. Holloway KL, Barnes T, Choi S, Bullock R, Marshall LF, Eisenberg HM, et al: Ventriculostomy infections: the effect of monitoring duration and catheter exchange in 584 patients. J Neurosurg 85:419-424, 1996

10. Kochanek PM, Carney N, Adelson PD, Ashwal S, Bell MJ, Bratton S, et al: Guidelines for the acute medical management of severe traumatic brain injury in infants, children, and adolescents - second edition. Pediatr Crit Care Med 13 (Suppl 1):S1-S82, 2012

11. Lang JM, Beck J, Zimmermann M, Seifert V, Raabe A: Clinical evaluation of intraparenchymal Spiegelberg pressure sensor. Neurosurgery 52:1455-1459, 2003

12. Mayhall CG, Archer NH, Lamb VA, Spadora AC, Baggett JW, Ward JD, et al: Ventriculostomy-related infections. A prospective epidemiologic study. N Engl J Med 310:553559,1984

13. Narayan RK, Kishore PR, Becker DP, Ward JD, Enas GG, Greenberg RP, et al: Intracranial pressure: to monitor or not to monitor? A review of our experience with severe head injury. J Neurosurg 56:650-659, 1982

14. Paramore CG, Turner DA: Relative risks of ventriculostomy infection and morbidity. Acta Neurochir (Wien) 127:79-84, 1994

15. Raksin PB, Alperin N, Sivaramakrishnan A, Surapaneni S, Lichtor T: Noninvasive intracranial compliance and pressure based on dynamic magnetic resonance imaging of blood flow and cerebrospinal fluid flow: review of principles, implementation, and other noninvasive approaches. Neurosurg Focus 14(4): 4,2003

16. Roumeliotis N, Pettersen G, Crevier L, Émeriaud G: ICP monitoring in children: why are we not adhering to guidelines? Childs Nerv Syst 31:2011-2014, 2015

17. Rutland-Brown W, Langlois JA, Thomas KE, Xi YL: Incidence of traumatic brain injury in the United States, 2003. J Head Trauma Rehabil 21:544-548, 2006

18. Wall SA, Thomas GP, Johnson D, Byren JC, Jayamohan J, Magdum SA, et al: The preoperative incidence of raised intracranial pressure in nonsyndromic sagittal craniosynostosis is underestimated in the literature. J Neurosurg Pediatr 14:674-681, 2014

\section{Disclosures}

The authors report no conflict of interest concerning the materials or methods used in this study or the findings specified in this paper.

\section{Author Contributions}

Conception and design: Behmanesh. Acquisition of data: Behmanesh, Noack, Bartels, Quick-Weller. Analysis and interpretation of data: Behmanesh. Drafting the article: Behmanesh. Statistical analysis: Behmanesh, Setzer. Study supervision: Seifert, Freiman.

\section{Correspondence}

Bedjan Behmanesh, Department of Neurosurgery, University Hospital, Schleusenweg 2-16, Frankfurt 60528, Germany. email: bedjan.behmanesh@kgu.de. 